\title{
Association of active Helicobacter pylori infection and anemia in elderly males
}

\author{
Baicun Hou', Meifang Zhang ${ }^{1}$, Miao Liu², Wei Dai ${ }^{3}$, Yunjuan Lin', Yuan Li', Meiliang Gong ${ }^{4}$ and Gangshi Wang ${ }^{1 *}$ (D)
}

\begin{abstract}
Background: The prevalence of Helicobacter pylori (H. pylori) infection increases with age. However, the relationship between $\mathrm{H}$. pylori infection and anemia in the elderly population remains to be identified. The aim of this study is to explore whether $\mathrm{H}$. pylori infection is associated with anemia in a male elderly cohort.

Methods: A cross-sectional study was designed using data collected from asymptomatic male senior citizens ( $\geq 65$ years old) who received an assessment of their health status at the General Hospital of Chinese PLA from January 2015 to December 2015. H. pylori infection was confirmed by the ${ }^{13} \mathrm{C}$-urea breath test. Blood samples from the participants were taken to assay for hemoglobin and other erythroid-related indices - serum iron, ferritin, and C-reactive protein (CRP). Anemia was defined as hemoglobin values lower than $120.0 \mathrm{~g} / \mathrm{L}$. Charlson Comorbidity Index (CCl) was applied to establish baseline comorbidities.

Results: Data from 646 subjects were analyzed. The mean age of the study cohort was $79.4 \pm 8.9$ years. The overall prevalence of $\mathrm{H}$. pylori infection was $35.3 \%$. The prevalence of anemia in the $\mathrm{H}$. pylori positive group was higher than that in the negative group (5.3\% vs. $2.2 \%, P=.033$ ). Among the patients who had higher $\mathrm{CCl}$ scores $(>2)$, the prevalence of anemia in the $H$. pylori positive and negative groups were 10.3 and $1.4 \%$, respectively $(P=.009)$. Compared to the $H$. pylori negative group, the odds ratio for anemia of the $H$. pylori positive group was $2.53(P=.033)$. No correlation between $H$. pylori infection and serum iron and ferritin levels was found. The mean corpuscular volume of the H. pylori positive and negative group was $91.17 \pm 3.94 \mathrm{fl}$ and $91.17 \pm 4.09 \mathrm{fl}$ (mean $\pm \mathrm{SD}$ ), respectively $(P=.986)$. The CRP level in the $H$. pylori positive group was higher than that in the $H$. pylori negative group (Median: $0.17 \mathrm{mg} / \mathrm{dL}$ vs. $0.10 \mathrm{mg} / \mathrm{dL}, P<.001)$.
\end{abstract}

Conclusion: H. pylori infection seems to be associated with normocytic and normochromic anemia in elderly males, especially in those with more comorbidities. Further clinical studies are needed to verify the association.

Keywords: Helicobacter pylori, Anemia, Elderly

\section{Background}

Epidemiological studies have revealed a correlation between Helicobacter pylori (H. pylori) infection and some non-gastrointestinal diseases, especially those characterized by persistent and low-grade systemic inflammation [1-3]. Idiopathic iron deficiency anemia (IDA) is a well-recognized extragastric manifestation of H. pylori infection and has already been fully accepted and included in the current guidelines for these

\footnotetext{
* Correspondence: wanggangshi@hotmail.com

'Department of Gastroenterology, The Second Medical Center, Chinese PLA General Hospital and National Clinical Research Center for Geriatric Diseases, Beijing 100853, People's Republic of China

Full list of author information is available at the end of the article
}

conditions [1, 2, 4, 5]. After the first report of a young adult whose long-standing IDA was reversed after H. pylori eradication [6], some additional trials indicated that $H$. pylori infection is associated with an increased likelihood of depleted iron storage, and H. pylori eradication therapy might be beneficial, in terms of increasing ferritin levels [7-10]. Reported data have supported the effectiveness of $H$. pylori treatment in patients with moderate to severe anemia when compared to those with mild anemia [11]. However, it should be noted that the most convincing data for the association between H. pylori infection and IDA come from meta-analyses. Meanwhile, there are also reports of conflicting findings

(c) The Author(s). 2019 Open Access This article is distributed under the terms of the Creative Commons Attribution 4.0 International License (http://creativecommons.org/licenses/by/4.0/), which permits unrestricted use, distribution, and 
on the relationship between $H$. pylori and iron storage [12-15]. Shak JR et al. even found that H. pylori seropositivity was negatively associated with anemia [16].

It has recently been recommended that $H$. pylori infection be tested and treated in persons with unexplained IDA $[5,17]$. The consensus was reached based on studies in which most of the subjects were children, adolescents and middle-age adults. There is no guideline or consensus on $H$. pylori management in the elderly population until now. Few data on the effects of $H$. pylori infection on anemia and iron storage in the elderly population were presented. Kaffes et al. observed an association of H. pylori infection with significantly lower ferritin levels only in elderly female aspirin users, which indicated that $H$. pylori infection may play a role in iron storage in this population [18]. A small survey performed in asymptomatic elderly subjects found that nutritional indices, including hemoglobin, iron, ferritin and transferrin, were not influenced by the presence of anti-HP antibodies [14]. The relationship between anemia and $H$. pylori infection in the elderly has so far not been established. It is evident that the prevalence of $H$. pylori infection increases with age in developing countries [19-21]. Since medical decision making for the elderly is difficult due to their declining physical and cognitive functions and social support, anemia is associated with an increased mortality risk in persons aged 85 years and older [22], it is meaningful to study if $H$. pylori infection is associated with anemia in this population.

In this study of an asymptomatic elderly cohort presenting active $H$. pylori infection, which was identified with the ${ }^{13} \mathrm{C}$-urea breath test $\left({ }^{13} \mathrm{C}\right.$-UBT $)$, we examined if they have a higher prevalence of anemia when compared to their counterparts with no evidence of active $H$. pylori infection. Elderly people are often presented with chronic diseases, which are major confounders in longitudinal non-randomized studies. When adjusted for comorbidities, researchers may consider comorbidities individually or through the use of summary measures, such as the Charlson Comorbidity Index (CCI). We applied the CCI scores to adjust the baseline comorbidities, in order to remove the possible confounding factors which may cause anemia in this study. We also assessed the effects of $H$. pylori infection on the level of serum iron, ferritin and C-reactive protein (CRP).

\section{Methods}

\section{Study subjects}

This study is conducted with a cohort of male senior citizens (age $\geq 65$ years) who received an assessment of their health status at the Chinese PLA General Hospital from January 2015 to December 2015. All participants received the ${ }^{13} \mathrm{C}$-UBT examination. Exclusion criteria included use of antibiotics, bismuth, or proton pump inhibitor (PPI) and $\mathrm{H}_{2}$-receptor antagonist within 4 weeks. On the same day of the ${ }^{13} \mathrm{C}$-UBT, blood samples were collected for complete blood count, and serum iron and ferritin measurements. Serum CRP level was also tested in individuals who have available serum samples. Stool samples were obtained for occult assessment. A detailed clinical history was taken to record any significant acute or chronic illnesses that may cause anemia, such as neoplasia at advanced stages, hematologic disorders, chronic kidney diseases, gastrectomy, malnutrition, acquired immunosuppression, evident gastrointestinal bleeding, and ongoing inflammatory diseases, etc.. In addition, comorbid diseases of each participant were collected and CCI were applied to establish baseline comorbidities. The CCI is based on a number of conditions that are each assigned an integer weight from one to six, with a weight of six representing the most severe morbidity. The summation of the weighted comorbidity scores results in a summary score [23], which can give clinicians and researchers a single number that captures the individual's health status.

Patients with evident gastrointestinal cancer, hematologic disorders, who received iron supplementation for at least 30 days, received erythropoietin injection, those with overt/occult gastrointestinal bleeding, with malnutrition, a history of gastrectomy, and those with recent hospitalization due to acute illnesses were excluded. This study was approved by the Ethics Committee of the General Hospital of Chinese PLA.

\section{H. pylori status}

H. pylori status was evaluated by the ${ }^{13} \mathrm{C}$-UBT, which was performed in the morning after fasting for at least $8 \mathrm{~h}$. Breath samples were collected from each subject at baseline and $30 \mathrm{~min}$ after drinking $70 \mathrm{~mL}$ of roomtemperature water containing $75 \mathrm{mg}$ of ${ }^{13} \mathrm{C}$-urea. An additional breath sample was collected 30 min after the ingestion of the tracer. The test was performed with a ${ }^{13} \mathrm{C}$-breath test instrument (Fischer Analysen Instrumente $\mathrm{GmbH}$, Leipzig, Germany). The results were expressed as a surplus of isotopic ratio over the baseline isotopic ratio (delta over baseline [DOB]). A DOB value of $>4 \%$ was considered positive, according to the instructions from the test manufacturer.

\section{Clinical tests}

Blood counts were determined using an automated electronic counter (Sysmex XN3000, Sysmex Corporation, Kobe, Japan). The serum concentration of ferritin was determined by an electrochemiluminescence immunoassay 
(Cobas e601, Roche Diagnostics Ltd., Switzerland). The serum levels of iron and CRP were also determined by electrochemiluminescence immunoassay (Cobas c501, Roche Diagnostics Ltd., Switzerland). The reference ranges for serum iron and ferritin were $7-32 \mu \mathrm{mol} / \mathrm{L}$ and 30-400 ng/mL, respectively. The reference range for mean corpuscular volume (MCV) was $80-100 \mathrm{fl}$, and that for CRP was $0-0.8 \mathrm{mg} / \mathrm{dL}$. The World Health Organization defines anemia in the adult or elderly populations as hemoglobin concentrations below the level of $120 \mathrm{~g} / \mathrm{L}$ for non-pregnant women, and $130 \mathrm{~g} / \mathrm{L}$ for men [24]. The use of this criterion in the elderly population has been questioned because these cutoff levels were derived from statistical distributions in a study in which the participants were healthy and young. We use a hemoglobin concentration of lower than $120 \mathrm{~g} / \mathrm{L}$ as the cutoff value for anemia in this study, based on both the data described in the literatures and the normal range $(110-176 \mathrm{~g} / \mathrm{L})$ of the test system we applied. A cutoff value of $130 \mathrm{~g} / \mathrm{L}$ was used in sensitivity analyses.

\section{Statistical analysis}

Statistical analyses were performed using Statistical Package for SPSS (Windows version 19.0). Continuous variables were expressed as ${ }^{-} \mathrm{x} \pm \mathrm{s}$ for variables of normal distribution and median (interquartile range) for variables of skewness distribution. Categorical variables were expressed as $\mathrm{n}(\%)$. $\mathrm{T}$ test, $\mathrm{\chi} 2$ test and nonparametric test were used to examine the differences in the corresponding continuous and categorical variables. Multivariable logistic regression was used to calculate the odds ratios (ORs) and 95\% confidence intervals (CIs). Two-sided $P$ value $<.05$ was considered as statistically significant.

\section{Results}

General information and baseline diseases of participants Results from 646 subjects were available for analysis. The mean age was $79.4 \pm 8.9$ years, with a range of 65-100 years. Baseline diseases which may cause a decrease in hemoglobin concentration were documented (Table 5 in Appendix). The comorbidities were measured by CCI, with an average CCI score of 1.93 in the 646 subjects. The prevalence of $\mathrm{H}$. pylori infection was $35.3 \%$. The subjects were further divided into three subgroups based on their age [65-74 years group $(n=239), 75-84$ years group $(n=162), \geq 85$ years group $(n=245)]$. As summarized in Table 1, the CCI score and prevalence of comorbidities increased significantly with age $(P<.001)$. There is no difference in the levels of hemoglobin, serum iron and ferritin, as well as $H$. pylori prevalence, among the three subgroups $(P>.05)$ (Table 1$)$.

\section{H. pylori status and hematological parameters}

Twenty-one cases with hemoglobin less than $120 \mathrm{~g} / \mathrm{L}$ were observed in this cohort (Table 6 in Appendix). In general, the prevalence of anemia in the $H$. pylori positive group was higher than that in the negative group (5.3\% vs $2.2 \%, P=.033$ ). The hemoglobin concentration was slightly lower in the $H$. pylori positive group than in the negative group, but with no statistical significance (mean \pm SD, $144.83 \pm 13.77 \mathrm{~g} / \mathrm{L}$ vs. $146.57 \pm 13.11 \mathrm{~g} / \mathrm{L}$, $P=.115)$. Either age or CCI score alone had no effects on anemia prevalence or hemoglobin levels (Table 2). When using hemoglobin $130 \mathrm{~g} / \mathrm{L}$ as a cutoff value for anemia, the odds ratio (OR) of $H$. pylori positive on anemia prevalence was 1.27 (95\% CI: $0.78-2.07 ; P=.332$ ), compared with the H. pylori negative group (Table 7 in Appendix).

Table 1 General Characteristics of participants according to different age groups

\begin{tabular}{|c|c|c|c|c|c|}
\hline \multirow[t]{2}{*}{ Characteristics } & \multicolumn{3}{|l|}{ Age group (years) } & \multirow[t]{2}{*}{$P$ value } & \multirow[t]{2}{*}{ Total $(n=646)$} \\
\hline & $65 \sim 74$ years $(n=239)$ & $75 \sim 84$ years $(n=162)$ & $\geq 85$ years $(n=245)$ & & \\
\hline \multicolumn{6}{|l|}{ Mean \pm SD } \\
\hline Age (years) & $69.48 \pm 2.78$ & $79.72 \pm 2.97$ & $88.87 \pm 3.11$ & $<0.001$ & $79.40 \pm 8.90$ \\
\hline Hemoglobin(g/L) & $145.91 \pm 13.39$ & $145.76 \pm 13.09$ & $146.14 \pm 13.58$ & 0.959 & $145.96 \pm 13.36$ \\
\hline $\mathrm{MCV}(\mathrm{fl})$ & $91.36 \pm 4.47$ & $90.57 \pm 3.82$ & $91.39 \pm 3.70$ & 0.084 & $91.18 \pm 4.04$ \\
\hline Serum iron $(\mu \mathrm{mol} / \mathrm{L})$ & $20.47 \pm 6.49$ & $19.97 \pm 5.55$ & $19.25 \pm 5.57$ & 0.076 & $19.88 \pm 5.94$ \\
\hline CCl score & $1.55 \pm 1.27$ & $1.95 \pm 1.53$ & $2.28 \pm 1.68$ & $<0.001$ & $1.93 \pm 1.53$ \\
\hline \multicolumn{6}{|l|}{ Median (IQR) } \\
\hline Serum ferritin (ng/mL) & $180.50(110.80-256.50)$ & $165.50(109.80-272.75)$ & $186.10(107.30-273.60)$ & 0.903 & 179.55 (110.08-268.10) \\
\hline \multicolumn{6}{|l|}{ N (\%) } \\
\hline Malignant tumor & $22(9.2)$ & $30(18.5)$ & 45 (18.4) & 0.005 & $97(15.0)$ \\
\hline Other comorbidities & $13(5.4)$ & $25(15.4)$ & $65(26.5)$ & $<0.001$ & $103(15.9)$ \\
\hline H. pylori positive & 85 (35.6) & $59(36.4)$ & $84(34.3)$ & 0.767 & $228(35.3)$ \\
\hline
\end{tabular}


Table 2 Anemia prevalence and hemoglobin levels according to age, $\mathrm{CCl}$ score and $\mathrm{H}$. pylori status

\begin{tabular}{|c|c|c|c|c|c|}
\hline \multirow[t]{2}{*}{ Characteristics } & \multirow{2}{*}{$\begin{array}{l}\text { Number } \\
\text { of cases }\end{array}$} & \multicolumn{2}{|c|}{ Anemia prevalence } & \multicolumn{2}{|c|}{ Hemoglobin (g/L) } \\
\hline & & n (\%) & $P$ value & Mean \pm SD & $P$ value \\
\hline Age & & & 0.845 & & 0.959 \\
\hline $65-74$ years & 239 & $9(3.8)$ & & $145.91 \pm 13.39$ & \\
\hline $75-84$ years & 162 & $5(3.1)$ & & $145.76 \pm 13.09$ & \\
\hline$\geq 85$ years & 245 & $7(2.9)$ & & $146.14 \pm 13.58$ & \\
\hline CCl score & & & 0.442 & & 0.891 \\
\hline$\leq 2$ & 449 & $13(2.9)$ & & $145.91 \pm 13.42$ & \\
\hline$>2$ & 197 & $8(4.1)$ & & $146.06 \pm 13.27$ & \\
\hline H. pylori status & & & 0.033 & & 0.115 \\
\hline positive & 228 & $12(5.3)$ & & $144.83 \pm 13.77$ & \\
\hline negative & 418 & $9(2.2)$ & & $146.57 \pm 13.11$ & \\
\hline
\end{tabular}

The relationship between anemia and $H$. pylori status according to CCI scores and age were further analyzed. The difference of anemia prevalence in each age subgroups remained to be around $3 \%$, but was of no statistical significance. The average CCI scores of $H$. pylori positive and negative group was 1.85 and 1.97 , respectively $(P=.643)$. No relation between CCI scores and anemia was found in this study population. The prevalence of anemia in high $(>2)$ and low $(\leq 2)$ CCI score groups was 4.1 and $2.9 \%$, respectively $(P=.442)$. Among the patients with low CCI score $(\leq 2)$, there was no significant difference of the anemia prevalence between the $H$. pylori positive and negative groups ( $3.5 \%$ vs. $2.5 \%$,
Table 4 ORs and 95\% Cl of H. pylori positive on anemia prevalence

\begin{tabular}{lccc}
\hline Variable & OR & $95 \% \mathrm{Cl}$ & $P$ value \\
\hline Total population $(\mathrm{n}=646)$ & \multicolumn{4}{c}{} \\
$\quad$ Crude & 2.53 & $1.05-6.09$ & 0.033 \\
Age and CCl adjusted & 2.57 & $1.06-6.21$ & 0.036 \\
Population without malignant tumor $(\mathrm{n}=549)$ & \\
$\quad$ Crude & 2.29 & $0.96-5.54$ & 0.065 \\
Age and CCl adjusted & 2.42 & $0.99-5.89$ & 0.051 \\
Population with normal MCV $(n=631)$ & & \\
$\quad$ Crude & 2.58 & $1.02-6.50$ & 0.045 \\
Age and CCl adjusted & 2.56 & $1.02-6.46$ & 0.040 \\
\hline
\end{tabular}

$P=.569)$. However, among the patients who had higher CCI scores $(>2)$, the prevalence of anemia was higher in the $H$. pylori positive group than those in the negative group (10.3\% vs.1.4\%, $P=.009)$ (Table 3 ).

Table 4 shows the OR of $H$. pylori status on anemia prevalence. Compared with the $H$. pylori negative individuals, the crude OR of $H$. pylori status on anemia prevalence was 2.53 (95\% CI: 1.05-6.09; $P=.033$ ). We also adjusted for age and CCI scores in the logistic regression. The results were similar. In the sensitivity analysis, we calculated the ORs of $H$. pylori status on anemia among those without malignant tumors $(n=549)$, the age-adjusted OR was 2.30 (95\% CI: $0.95-5.55)$.

Table 3 Relationship between anemia and H. pylori status according to age and CCl score

\begin{tabular}{|c|c|c|c|c|c|}
\hline characteristic & & Number of cases & Anemia prevalence $\mathrm{n}(\%)$ & Difference (95\% Cl) & $P$ value \\
\hline \multirow[t]{9}{*}{ Age group } & $65-74$ years & & & & \\
\hline & H. pylori positive & 85 & $5(5.9)$ & $3.3(-2.3$ to 8.9$)$ & 0.202 \\
\hline & H. pylori negative & 154 & $4(2.6)$ & & \\
\hline & $75-84$ years & & & & \\
\hline & H. pylori positive & 59 & $3(5.1)$ & $3.1(-3.1$ to 9.4$)$ & 0.266 \\
\hline & H. pylori negative & 103 & $2(1.9)$ & & \\
\hline & $\geq 85$ years & & & & \\
\hline & H. pylori positive & 84 & $4(4.8)$ & $2.9(-2.1$ to 7.9$)$ & 0.196 \\
\hline & H. pylori negative & 161 & $3(1.9)$ & & \\
\hline \multirow[t]{6}{*}{ CCl score } & $\leq 2$ & & & & \\
\hline & H. pylori positive & 170 & $6(3.5)$ & $1.0(-2.3$ to 4.4$)$ & 0.569 \\
\hline & H. pylori negative & 279 & $7(2.5)$ & & \\
\hline & $>2$ & & & & \\
\hline & H. pylori positive & 58 & $6(10.3)$ & 8.9 (0.8 to 17.0$)$ & 0.009 \\
\hline & H. pylori negative & 139 & $2(1.4)$ & & \\
\hline
\end{tabular}


Erythroid-related indices for both the $H$. pylori positive and negative groups were analyzed. Hematocrit (HCT) had a marginal difference between the $H$. pylori positive and negative groups $(P=.058)$. The MCV of the $H$. pylori positive and negative group was $91.17 \pm 3.94 \mathrm{fl}$ and $91.18 \pm 4.09 \mathrm{fl}$ (mean $\pm \mathrm{SD}, P=.986$ ), respectively. Other erythroid-related indices showed no significant difference among either $H$. pylori status $(P>.05)$ (Table 8 in Appendix).

\section{Effect of $H$. pylori status on serum iron, ferritin and CRP levels}

Similar serum iron levels were found in the H. pylori positive and negative groups (mean $\pm \mathrm{SD}, 19.90 \pm 6.24 \mu \mathrm{mol} / \mathrm{L}$ vs. $19.87 \pm 5.78 \mu \mathrm{mol} / \mathrm{L}, \quad P=.961)$. The results were found to be similar for serum ferritin. The median serum ferritin was $174.00 \mathrm{ng} / \mathrm{mL}$ (IQR 108.78-267.88) in the $H$. pylori positive group, and $181.65 \mathrm{ng} / \mathrm{mL}$ (IQR 110.68-270.60) in the $H$. pylori negative group $(P=.613)$.

Among the subjects recruited in this study, CRP data were available in 262 cases, which included $66 \mathrm{H}$. pylori positive and $196 \mathrm{H}$. pylori negative ones. Although all the subjects represent CRP within the normal range, the CRP level in the $H$. pylori positive group (Median: $0.17 \mathrm{mg} / \mathrm{dL}$, IQR: 0.10-0.69) was higher than that in the $H$. pylori negative group (Median: $0.10 \mathrm{mg} / \mathrm{dL}$; IQR: 0.07-0.23) $(P<.001)$.

\section{Discussion}

The prevalence of $H$. pylori infection increases with age, with about $50 \%$ of the population infected at ages above 60 , and around $10 \%$ between 18 and 30 [19]. H. pylori infections are usually acquired in early childhood in all countries [25]. Therefore, it is reasonable to assume that chronic $H$. pylori infections in the elderly can cause anemia due to predisposition to gastrointestinal mucosal lesions [26].

Among the 646 elderly male subjects, we found a significant association between $H$. pylori infection and anemia. The prevalence of anemia in the positive group was higher than that in the negative group, with a difference of about $3 \%$. This is consistent with the mainstream opinion that anemia is considered as a complication of $H$. pylori infection [9, 27-29]. A strong association between $H$. pylori infection and anemia (OR 2.53, 95\% CI 1.05-6.09) was observed in this study. A similar result was reported in a recent study. $\mathrm{Xu}$ et al. found that when compared to $H$. pylori negative groups, the OR of the $H$. pylori positive group was 2.01 (95\% CI: 0.92-4.40) for mild anemia and 2.41 (95\% CI: 0.91-6.34) for moderate-to-severe anemia in male subjects after adjusting for potential confounders [27]. Because of the low prevalence of anemia in this special cohort, no significant difference of average hemoglobin levels between the $H$. pylori positive and negative groups (mean $\pm \mathrm{SD}$, $144.83 \pm 13.77 \mathrm{~g} / \mathrm{L}$ vs. $146.57 \pm 13.11 \mathrm{~g} / \mathrm{L}, P=.115$ ) was found, although the positive group did show a slightly lower hemoglobin level than the negative group.

In elderly subjects, the "accepted" cutoff values for the diagnosis of anemia vary between countries, regions and laboratories [30]. The hemoglobin concentration is lower on average in older people [31]. A significant association between $H$. pylori infection and anemia was found by using hemoglobin concentration of lower than $120 \mathrm{~g} / \mathrm{L}$ as the cutoff value for anemia in this study. This association was corroborated by a further sensitivity analysis when using the cutoff value of $130 \mathrm{~g} / \mathrm{L}$, in which the OR of $H$. pylori positive on anemia prevalence was 1.27 . The anemia prevalence (hemoglobin cutoff value of $120 \mathrm{~g} / \mathrm{L}$ ) in this cohort was $3.3 \%$, which was lower than that reported in the literatures. The anemia prevalence of Chinese city population was recently reported as $9.7 \%$ (95\%CI: 9.4-10.1\%), 6.8\% (95\%CI: 6.4-7.3\%) for male and $12.8 \%$ (95\%CI: $12.2-13.4 \%$ ) for female, while $11.4 \%$ (95\%CI: 9.8-11.3\%) for male metropolis more than 60 years-old [32]. In this study, 77 cases of anemia could be identified if the cutoff value was set to $130 \mathrm{~g} / \mathrm{L}$. This prevalence $(11.9 \%)$ is similar to that reported in the literature. Furthermore, we excluded those with overt/occult gastrointestinal bleeding, with malnutrition and those received iron supplementation, etc., that some anemia patients related to nutritional deficiency or iron deficiency were eliminated from the cohort. Thus, the anemia prevalence in this study is relatively low.

We found no significant association between $H$. pylori infection and serum iron and ferritin levels. The question as to whether $H$. pylori infection plays a role in IDA has been widely studied. One updated systematic review and meta-analysis study has indicated an association between $H$. pylori infection and an increased likelihood of depleted iron storage [8]. On the contrary, some conflicting findings have been reported. A study in Australia of individuals aged $\geq 65$ years found no significant association, except among female aspirin users, which supports a negative effect of $H$. pylori on iron status [18]. A recent large cohort retrospective study also reported that after adjusting for potential confounders, subjects with $H$. pylori infection had a higher prevalence of normocytic anaemia [27]. Patients with gastrointestinal bleeding or those received iron supplementation were excluded in this study, the level of iron deficiency could be underestimated. $H$. pylori infection could induce mixed deficiencies such as concomitant iron and vitamin B12 
or folate deficiency, that would result in normocytic anemia. Owing to the normal iron and ferritin levels, as well as the normal erythroid-related parameters, we could exclude iron deficiency as a direct cause of normocytic and normochromic anemia in this study group. The absence of macrocytosis can help to infer that there might not be vitamin B12 deficiency in this cohort.

Apart from hematologic malignancies which accounted for $4 \%$ of anemia cases, some common causes of normocytic anemia encountered in the elderly included chronic inflammation, mixed nutrition deficiencies, chronic diseases and hemoglobinpathies [31]. Chronic inflammation is one of the most common causes of anemia in the elderly [33]. This type of anemia is typically normocytic and normochromic with mild to moderate reductions in hemoglobin level. Anemia of chronic inflammation is believed to be driven by immune responses [31, 34]. It is reported that $H$. pylori infection can cause systemic immune responses and chronic inflammation, that would subsequently induce the release of cytokines and inflammatory mediators such as interleukins 1 and 17, as well as tumor necrosis factor- $\alpha$ and interferon- $\gamma$ [35]. The work-up and diagnosis of unexplained anemia in the elderly may include the measurement of inflammatory markers such as CRP and erythrocyte sedimentation rate, interleukin-6, and hepcidin levels [36]. It is reported that $H$. pylori infection may increase the level of serum CRP [37]. In this study, although all the subjects presented CRP levels within the normal range, we revealed a higher serum CRP level in the H. pylori positive group than that in the negative group. The possible attribution of H. pylori infection to changes in serum CRP level could be through a complex route of inflammation that has yet to be elucidated.

It is noticeable in this study that in the H. pylori positive subjects of higher CCI scores $(>2)$, the prevalence of anemia was significantly higher than the negative ones with higher CCI scores (10.3\% vs. $1.4 \%)$. This indicates that $H$. pylori infection could have a strong association with anemia in people with more comorbidities. No independent effect of CCI scores on anemia or hemoglobin level was found in our study, which was different from what the literature reported [38]. This may be because the average CCI score $($ mean $=1.93)$ was low in this cohort, which means that the subjects in this study are in relatively good health, their comorbidities are not severe enough to affect their anemia prevalence. These subjects are from well-developed areas in China, who are also at a social-economic level much better than average as evident by their ability to take part in a routine annual health checkup. This can also partially explain the findings in this study that the prevalence of $H$. pylori infection was $35.2 \%$, which were lower than those cited by other studies conducted on the Chinese adult population [39]. The two similar CCI scores (1.85 vs. 1.97 ) in $H$. pylori positive and negative groups also helped to verify the effects of $H$. pylori infection, rather than comorbidities, on anemia in this special cohort.

Our study has several limitations. First, we used only ${ }^{13} \mathrm{C}$-UBT to determine current active $H$. pylori infection, which is believed to have better sensitivity and specificity than the serological assays [40]. ${ }^{13} \mathrm{C}$-UBT would present more false negative results in elderly population with more prevalence of atrophic gastritis [41], which may have biased the detection of $H$. pylori infection. It would be more meaningful if we have serological data and the patients could be classified into $H$. pylori negative, past $H$. pylori infection and current $H$. pylori infection subgroups. Second, we did not obtain the data on serum folate, vitamin B12 levels, which can potentially confound the causal relationship, although the absence of macrocytosis can help to address the issue. Besides, some residual confounders such as smoking and drinking are lacking, which may bias the analysis results. $H$. pylori eradication can increase the hemoglobin level in IDA patients [42], it would be meaningful if we can improve the normocytic and normochromic anemia after eradication in our cohort. This will be performed in our future study. Third, due to the nature of our institution, we could only study a relatively small sample, and limited to male subjects with a higher-than-average socio-economic status. Therefore, the results and conclusion are not representative of the population, even for the elderly, as a whole. Finally, we cannot confirm the actual causality between $H$. pylori infection and anemia as this is an observational study. Our hope is that other institutions will perform similar studies so that we can put together a more complete picture of how $H$. pylori infection affects the other clinical aspects of the elderly population.

\section{Conclusion}

In summary, our data seem to suggest a positive association between active $H$. pylori infection, as determined by ${ }^{13} \mathrm{C}$-UBT, and anemia in an elderly asymptomatic male cohort, especially in those with more comorbidities. No difference was observed between ${ }^{13} \mathrm{C}$-UBT positive and negative subjects with respect to erythroidrelated indices, serum iron or ferritin. More detailed studies are needed and could help to delineate the prevalence, and the mechanism of action that may lead to anemia after chronic $H$. pylori infection in the elderly. 


\section{Appendix}

Table 5 Summary of comorbidities measured in Charlson Comorbidity Index

\begin{tabular}{|c|c|c|c|}
\hline & Number of cases & & \\
\hline & $\begin{array}{l}\text { H. pylori positive } \\
(n=228)\end{array}$ & $\begin{array}{l}\text { H. pylori negative } \\
(n=418)\end{array}$ & Total $(n=646)$ \\
\hline Myocardial infaction & $5(2.2)$ & $13(3.1)$ & 18 \\
\hline Congestive heart failure & $3(1.3)$ & $6(1.4)$ & 9 \\
\hline Peripheral vascular disease & $90(39.5)$ & 137(32.8) & 227 \\
\hline Cerebrovascular disease & $40(17.5)$ & $89(21.3)$ & 129 \\
\hline Dementia & $2(0.9)$ & $1(0.2)$ & 3 \\
\hline COPD & $47(20.6)$ & $57(13.6)$ & 104 \\
\hline Connective tissue disease & $1(0.4)$ & $4(1.0)$ & 5 \\
\hline Peptic ulcer disease & $2(0.9)$ & $2(0.5)$ & 4 \\
\hline Diabetes mellitus & 63(27.6) & $117(28.0)$ & 180 \\
\hline Moderate to severe chronic kidney disease & $19(8.3)$ & $45(10.8)$ & 64 \\
\hline Hemiplegia & 0 & 0 & 0 \\
\hline Leukemia & 0 & 0 & 0 \\
\hline Malignant lymphoma & 0 & $1(0.2)$ & 1 \\
\hline Solid tumor ${ }^{a}$ & $22(9.6)$ & $75(18.0)$ & 97 \\
\hline Liver disease $^{\mathrm{b}}$ & $44(19.3)$ & $85(20.3)$ & 129 \\
\hline $\operatorname{AIDS}^{c}$ & 0 & 0 & 0 \\
\hline Total & 338 & 632 & 970 \\
\hline
\end{tabular}

aEcluding gastrointestinal malignant tumors

${ }^{\mathrm{b}}$ Only 2 cases of hepatic cirrhosis were presented, with no hypersplenism

'Acquired immunodeficiency syndrome

Table 6 Data of 21 anemia patients

\begin{tabular}{|c|c|c|c|c|c|c|c|c|c|c|c|c|c|}
\hline No. & $\mathrm{CCl}$ score & Tumor & age & DOB & H. pylori & Hemoglobin ( $\mathrm{g} / \mathrm{L})$ & $\mathrm{MCHC}(\mathrm{g} / \mathrm{L})$ & $\mathrm{MCH}(\mathrm{pg})$ & $\mathrm{MCV}(\mathrm{fl})$ & $\operatorname{RBC}(\times 10 \mathrm{e} 12 / \mathrm{L})$ & $\mathrm{HCT}(\mathrm{L} / \mathrm{L})$ & Serum iron $(\mu \mathrm{mol} / \mathrm{L})$ & Serum ferritin $(\mathrm{ng} / \mathrm{mL})$ \\
\hline$\overline{1}$ & 4 & 0 & 85 & 1.2 & 0 & 116 & 335 & 33.4 & 99.7 & 3.47 & 0.346 & 16.3 & 86.4 \\
\hline 2 & 0 & 0 & 73 & 23.9 & 1 & 114 & 328 & 28.4 & 86.8 & 4.01 & 0.348 & 11.3 & 206.908 \\
\hline 3 & 3 & 0 & 75 & 4.9 & 1 & 118 & 336 & 29.3 & 87.1 & 4.03 & 0.351 & 15 & 76.73 \\
\hline 4 & 3 & 0 & 94 & 4.8 & 1 & 118 & 311 & 29.4 & 94.5 & 4.01 & 0.379 & 18 & 193.5 \\
\hline 5 & 2 & 0 & 74 & 4.1 & 1 & 109 & 344 & 31.4 & 91.4 & 3.47 & 0.317 & 18.5 & 44.12 \\
\hline 6 & 2 & 0 & 72 & 12.8 & 1 & 112 & 327 & 32.8 & 100.3 & 3.41 & 0.342 & 33.9 & 779.3 \\
\hline 7 & 1 & 0 & 87 & 0.5 & 0 & 109 & 321 & 31.2 & 97.4 & 3.49 & 0.34 & 9.1 & 411.4 \\
\hline 8 & 1 & 0 & 69 & 4.3 & 1 & 111 & 327 & 30.4 & 92.9 & 3.65 & 0.339 & 15.5 & 47.08 \\
\hline 9 & 0 & 0 & 81 & 0.6 & 0 & 115 & 323 & 31 & 96 & 3.71 & 0.356 & 18.9 & 98.31 \\
\hline 10 & 2 & 0 & 68 & 0.1 & 0 & 118 & 326 & 29.6 & 90.7 & 3.99 & 0.362 & 13.2 & 89.63 \\
\hline 11 & 1 & 0 & 73 & 1.7 & 0 & 109 & 312 & 27.6 & 88.4 & 3.95 & 0.349 & 7.6 & 22.93 \\
\hline 12 & 6 & 0 & 93 & 31.8 & 1 & 115 & 325 & 31 & 95.4 & 3.71 & 0.354 & 8.3 & 141.9 \\
\hline 13 & 4 & 0 & 76 & 22.3 & 1 & 101 & 334 & 32.9 & 98.4 & 3.07 & 0.302 & 16.3 & 71.28 \\
\hline 14 & 3 & 0 & 91 & 38.3 & 1 & 119 & 324 & 30.7 & 94.8 & 3.87 & 0.367 & 15.7 & 90.86 \\
\hline 15 & 3 & 0 & 82 & 4.9 & 1 & 108 & 325 & 28.6 & 87.8 & 3.78 & 0.332 & 13.5 & 206.908 \\
\hline 16 & 3 & 0 & 89 & 3.5 & 0 & 102 & 324 & 33 & 101.9 & 3.09 & 0.315 & 10.3 & 399.9 \\
\hline 17 & 2 & 0 & 73 & 11 & 1 & 117 & 346 & 32.1 & 92.6 & 3.65 & 0.338 & 11.8 & 140.3 \\
\hline 18 & 1 & 0 & 90 & 5.5 & 1 & 118 & 341 & 33.3 & 97.7 & 3.54 & 0.346 & 21.3 & 170.7 \\
\hline 19 & 1 & 0 & 70 & 1 & 0 & 110 & 322 & 31.8 & 98.8 & 3.46 & 0.342 & 18.2 & 57.82 \\
\hline 20 & 1 & 0 & 76 & 0.1 & 0 & 117 & 367 & 34.8 & 94.9 & 3.36 & 0.319 & 16.2 & 146.5 \\
\hline 21 & 0 & 0 & 70 & 0.5 & 0 & 111 & 339 & 30.2 & 88.9 & 3.68 & 0.327 & 12.9 & 350.5 \\
\hline
\end{tabular}

Note: Tumor: the status of advanced malignant tumor, 0-negative; 1-positive; The status of H. pylori: 0-negative;1-positive; DOB: delta over baseline value of ${ }^{13} \mathrm{C}-\mathrm{UBT}$ 
Table 7 Anemia prevalence (using hemoglobin $130 \mathrm{~g} / \mathrm{L}$ as cutoff value) according to $H$. pylori status

\begin{tabular}{llllc}
\hline H. pylori status & $\mathrm{n}(\%)$ & $\mathrm{OR}$ & $95 \% \mathrm{Cl}$ & $P$ value \\
\hline positive & $31(13.6)$ & 1.27 & $0.78-2.07$ & 0.332 \\
negative & $46(11.0)$ & 1.00 (Ref) & & \\
\hline
\end{tabular}

Table 8 Effect of H. pylori status on erythroid-related index

\begin{tabular}{|c|c|c|c|}
\hline \multirow[t]{2}{*}{ Variables } & \multicolumn{2}{|c|}{ Number of cases (\%) } & \multirow{2}{*}{$\begin{array}{l}P \\
\text { value }\end{array}$} \\
\hline & H. pylori positive & H. pylori negative & \\
\hline $\mathrm{MCHC}$ & & & .582 \\
\hline$<320 \mathrm{~g} / \mathrm{L}$ & $9(3.9)$ & $20(4.8)$ & \\
\hline $320-360 \mathrm{~g} / \mathrm{L}$ & $212(93.0)$ & $390(93.3)$ & \\
\hline$>360 \mathrm{~g} / \mathrm{L}$ & $7(3.1)$ & $8(1.9)$ & \\
\hline $\mathrm{MCH}$ & & & .987 \\
\hline$<27 \mathrm{pg}$ & $2(0.9)$ & $4(1.0)$ & \\
\hline $27-34 \mathrm{pg}$ & $223(97.8)$ & $408(97.6)$ & \\
\hline$>34$ pg & $3(1.3)$ & $6(1.4)$ & \\
\hline MCV & & & .544 \\
\hline$<80 \mathrm{fl}$ & $0(0.0)$ & $2(0.5)$ & \\
\hline $80-100 \mathrm{fl}$ & $224(98.2)$ & $407(97.4)$ & \\
\hline$>100 \mathrm{fl}$ & $4(1.8)$ & $9(2.2)$ & \\
\hline RBC & & & .372 \\
\hline$<3.5^{*} 10 \mathrm{e} 12 / \mathrm{L}$ & $4(1.8)$ & $7(1.7)$ & \\
\hline $3.5-5.5 * 10 \mathrm{e} 12 / \mathrm{L}$ & $214(93.9)$ & 381 (91.1) & \\
\hline$>5.5^{*} 10 \mathrm{e} 12 / \mathrm{L}$ & $10(4.4)$ & $30(7.2)$ & \\
\hline HCT & & & .058 \\
\hline$<0.35 \mathrm{~L} / \mathrm{L}$ & $21(9.2)$ & $20(4.8)$ & \\
\hline $0.35-0.52 \mathrm{~L} / \mathrm{L}$ & $205(89.9)$ & $396(94.7)$ & \\
\hline$>0.52 \mathrm{~L} / \mathrm{L}$ & $2(0.9)$ & $2(0.5)$ & \\
\hline RDW & & & .391 \\
\hline$<14.5 \%$ & $2(0.9)$ & $7(1.7)$ & \\
\hline$\geq 14.5 \%$ & $226(99.1)$ & $411(98.3)$ & \\
\hline
\end{tabular}

\section{Abbreviations}

${ }^{13} \mathrm{C}$-UBT: ${ }^{13} \mathrm{C}$-urea breath test; AIDS: Acquired immunodeficiency syndrome; CCl: Charlson comorbidity index; Cls: Confidence intervals; CRP: C-reactive protein; DOB: Delta over baseline value of ${ }^{13} \mathrm{C}-U B T$; $H$. pylori: Helicobacter pylori; $\mathrm{HCT}$ : Hematocrit; IDA: Iron deficiency anemia; MCH: Mean corpuscular hemoglobin; MCHC: Mean corpuscular hemoglobin concentration; MCV: Mean corpuscular volume; OR: Odds ratio; PPI: Proton pump inhibitor; RBC: Red blood cell; RDW: Red blood cells volume distribution width

\section{Acknowledgements}

We would like to thank Prof. Dezhong J. Liao and Dr. Lucas Zellmer at the Medical School of Minnesota University, Dr. Timothy K. Lee at Food and Drug Administration, USA, for their excellent English editing of the manuscript.

\section{Funding}

This study was supported by National Natural Science Foundation of China (grant number 51471186). The funder had no role in the study design, data collection and analysis, decision to publish, or manuscript preparation.

\section{Availability of data and materials}

The datasets used and/or analyzed during the current study will be made available from the corresponding author on reasonable request.

\section{Authors' contributions}

BCH performed the study, drafted the manuscript. MFZ, WD and YJL participated in the clinical data collection and analyses. ML performed the statistical analysis. YL and MLG carried out the 13C-UBT and clinical tests. GSW conceived of and guided the study, performed critical revision of the manuscript. All authors read and approved the final manuscript.

\section{Ethics approval and consent to participate}

All procedures performed in this study involving human participants were in accordance with the ethical standards of the institutional (Chinese PLA General Hospital) and/or national research committee and with the 1964 Helsinki declaration and its later amendments. Since this is a retrospective statistical analysis based on electronic health records collected as part of standard healthcare, without disclosing the patients' identity, no individual patients were directly contacted for the data. The need of consent was waived by the institutional ethical committee of the Chinese PLA General Hospital.

\section{Consent for publication}

Not applicable.

\section{Competing interests}

The authors declare that they have no competing interests.

\section{Publisher's Note}

Springer Nature remains neutral with regard to jurisdictional claims in published maps and institutional affiliations.

\section{Author details}

'Department of Gastroenterology, The Second Medical Center, Chinese PLA General Hospital and National Clinical Research Center for Geriatric Diseases, Beijing 100853, People's Republic of China. 'Department of Epidemiology, Institute of Geriatrics, The Second Medical Center, Chinese PLA General Hospital and National Clinical Research Center for Geriatric Diseases, Beijing 100853, People's Republic of China. ${ }^{3}$ Office of Information Management, The Second Medical Center, Chinese PLA General Hospital and National Clinical Research Center for Geriatric Diseases, Beijing 100853, People's Republic of China. ${ }^{4}$ Department of Clinical Laboratory, The Second Medical Center, Chinese PLA General Hospital and National Clinical Research Center for Geriatric Diseases, Beijing 100853, People's Republic of China.

Received: 6 March 2018 Accepted: 25 February 2019

Published online: 05 March 2019

\section{References}

1. Goni E, Franceschi F. Helicobacter pylori and extragastric diseases. Helicobacter. 2016;21(Suppl 1):45-8.

2. Franceschi F, Zuccala G, Roccarina D, Gasbarrini A. Clinical effects of helicobacter pylori outside the stomach. Nat Rev Gastroenterol Hepatol. 2014;11(4):234-42.

3. Franceschi F, Gasbarrini A, Polyzos SA, Kountouras J. Extragastric diseases and helicobacter pylori. Helicobacter. 2015;20(Suppl 1):40-6.

4. Papagiannakis P, Michalopoulos C, Papalexi F, Dalampoura D, Diamantidis $M D$. The role of helicobacter pylori infection in hematological disorders. Eur J Intern Med. 2013;24(8):685-90.

5. Malfertheiner P, Megraud F, O'Morain CA, Gisbert JP, Kuipers EJ, Axon AT, Bazzoli F, Gasbarrini A, Atherton J, Graham DY, et al. Management of helicobacter pylori infection-the Maastricht V/Florence consensus report. Gut. 2017;66(1):6-30

6. Marignani M, Angeletti S, Bordi C, Malagnino F, Mancino C, Delle Fave $G$, Annibale B. Reversal of long-standing iron deficiency anaemia 
after eradication of helicobacter pylori infection. Scand $J$ Gastroenterol. 1997;32(6):617-22.

7. Muhsen K, Cohen D. Helicobacter pylori infection and iron stores: a systematic review and meta-analysis. Helicobacter. 2008;13(5):323-40.

8. Hudak L, Jaraisy A, Haj S, Muhsen K. An updated systematic review and meta-analysis on the association between helicobacter pylori infection and iron deficiency anemia. Helicobacter. 2017;22(1):e12330

9. Xia W, Zhang X, Wang J, Sun C, Wu L. Survey of anaemia and helicobacter pylori infection in adolescent girls in Suihua, China and enhancement of iron intervention effects by H. Pylori eradication. Br J Nutr. 2012;108(2):357-62.

10. Cardenas VM, Prieto-Jimenez CA, Mulla ZD, Rivera JO, Dominguez DC, Graham DY, Ortiz M. Helicobacter pylori eradication and change in markers of iron stores among non-iron-deficient children in El Paso, Texas: an etiologic intervention study. J Pediatr Gastroenterol Nutr. 2011;52(3):326-32.

11. Yuan W, Li Y, Yang K, Ma B, Guan Q, Wang D, Yang L. Iron deficiency anemia in helicobacter pylori infection: meta-analysis of randomized controlled trials. Scand J Gastroenterol. 2010;45(6):665-76.

12. Shih HY, Kuo FC, Wang SS, Liu YC, Wu MC, Chang YP, Chiu GF, Chang PY, Wu DC, Hsieh MC, et al. Helicobacter pylori infection and Anemia in Taiwanese adults. Gastroenterol Res Pract. 2013;2013:390967.

13. Santos IS, Minten GC, Valle NC, Tuerlinckx GC, Boccio J, Barrado DA, Silva AB, Pereira GA. Helicobacter pylori and anemia: a communitybased cross-sectional study among adults in southern Brazil. Cad Saude Publica. 2009;25(12):2653-60.

14. Pilott A, Fabrello R, Franceschi M, Scagnelli M, Soffiati F, Di Mario F, Fortunato A, Valerio G. Helicobacter pylori infection in asymptomatic elderly subjects living at home or in a nursing home: effects on gastric function and nutritional status. Age Ageing. 1996;25(3):245-9.

15. Sarker SA, Mahmud H, Davidsson L, Alam NH, Ahmed T, Alam N, Salam MA, Beglinger C, Gyr N, Fuchs GJ. Causal relationship of helicobacter pylori with iron-deficiency anemia or failure of iron supplementation in children. Gastroenterology. 2008;135(5):1534-42.

16. Shak JR, Sodikoff JB, Speckman RA, Rollin FG, Chery MP, Cole CR, Suchdev PS. Anemia and helicobacter pylori seroreactivity in a rural Haitian population. Am J Trop Med Hyg. 2011;85(5):913-8.

17. Chey WD, Leontiadis Gl, Howden CW, Moss SF. ACG clinical guideline: treatment of helicobacter pylori infection. Am J Gastroenterol. 2017;112(2):212-39.

18. Kaffes A, Cullen J, Mitchell H, Katelaris PH. Effect of helicobacter pylori infection and low-dose aspirin use on iron stores in the elderly. J Gastroenterol Hepatol. 2003;18(9):1024-8.

19. Pounder RE, Ng D. The prevalence of helicobacter pylori infection in different countries. Aliment Pharmacol Ther. 1995;9(Suppl 2):33-9.

20. Bardhan PK. Epidemiological features of helicobacter pylori infection in developing countries. Clin Infect Dis : an official publication of the Infectious Diseases Society of America. 1997;25(5):973-8.

21. Queiroz DM, Carneiro JG, Braga-Neto MB, Fialho AB, Fialho AM, Goncalves MH, Rocha GA, Rocha AM, Braga LL. Natural history of helicobacter pylori infection in childhood: eight-year follow-up cohort study in an urban community in northeast of Brazil. Helicobacter. 2012;17(1):23-9.

22. Izaks GJ, Westendorp RG, Knook DL. The definition of anemia in older persons. Jama. 1999;281(18):1714-7.

23. Charlson ME, Pompei $P$, Ales KL, MacKenzie CR. A new method of classifying prognostic comorbidity in longitudinal studies: development and validation. J Chronic Dis. 1987;40(5):373-83.

24. Nutritional anaemias. Report of a WHO scientific group. World Health Organ Tech Rep Ser. 1968:405:5-37.

25. Kusters JG, van Vliet AH, Kuipers EJ. Pathogenesis of helicobacter pylori infection. Clin Microbiol Rev. 2006:19(3):449-90.

26. Tefferi A. Anemia in adults: a contemporary approach to diagnosis. Mayo Clin Proc. 2003;78(10):1274-80.

27. Xu MY, Cao B, Yuan BS, Yin J, Liu L, Lu QB. Association of anaemia with helicobacter pylori infection: a retrospective study. Sci Rep. 2017;7(1):13434.

28. Kibru D, Gelaw B, Alemu A, Addis Z. Helicobacter pylori infection and its association with anemia among adult dyspeptic patients attending Butajira hospital, Ethiopia. BMC Infect Dis. 2014;14:656.

29. Muhsen K, Barak M, Henig C, Alpert G, Ornoy A, Cohen D. Is the association between helicobacter pylori infection and anemia age dependent? Helicobacter. 2010;15(5):467-72.

30. Halawi R, Moukhadder H, Taher A. Anemia in the elderly: a consequence of aging? Expert Rev Hematol. 2017;10(4):327-35.
31. Beutler E, Waalen J. The definition of anemia: what is the lower limit of normal of the blood hemoglobin concentration? Blood. 2006;107(5):1747-50.

32. Hu Y, Chen J, Li M, Li W, Yang Y, Yang L, Wang R, Piao J. Study on the anemia status of Chinese urban residents in 2010-2012. Zhonghua yu fang yi xue za zhi [Chinese journal of preventive medicine]. 2016;50(3):213-6.

33. Bach V, Schruckmayer G, Sam I, Kemmler G, Stauder R. Prevalence and possible causes of anemia in the elderly: a cross-sectional analysis of a large European university hospital cohort. Clin Interv Aging. 2014;9:1187-96.

34. Weiss G, Goodnough LT. Anemia of chronic disease. N Engl J Med. 2005;352(10):1011-23.

35. D'Elios MM, Andersen LP. Inflammation, immunity, and vaccines for Helicobacter pylori. Helicobacter. 2009;14(Suppl 1):21-8.

36. Goodnough LT, Schrier SL. Evaluation and management of anemia in the elderly. Am J Hematol. 2014;89(1):88-96.

37. Ishida Y, Suzuki K, Taki K, Niwa T, Kurotsuchi S, Ando H, Iwase A, Nishio K, Wakai K, Ito Y, et al. Significant association between helicobacter pylori infection and serum C-reactive protein. Int J Med Sci. 2008;5(4):224-9.

38. Contreras Mdel M, Formiga F, Ferrer A, Chivite D, Padros G, Montero A. Profile and prognosis of patients over 85 years old with anemia living in the community. Octabaix Study. Rev Esp Geriatr Gerontol. 2015;50(5):211-5.

39. Wang KJ, Wang RT. Meta-analysis on the epidemiology of helicobacter pylori infection in China. Zhonghua Liu Xing Bing Xue Za Zhi = Zhonghua liuxingbingxue zazhi. 2003;24(6):443-6.

40. Gisbert JP, Pajares JM. Review article: 13C-urea breath test in the diagnosis of helicobacter pylori infection -- a critical review. Aliment Pharmacol Ther. 2004:20(10):1001-17.

41. Lahner E, Vaira D, Figura N, Pilozzi E, Pasquali A, Severi C, Perna F, Delle Fave $\mathrm{G}$, Annibale B. Role of noninvasive tests (C-urea breath test and stool antigen test) as additional tools in diagnosis of helicobacter pylori infection in patients with atrophic body gastritis. Helicobacter. 2010;9(5):436-42.

42. Yuan W, Yumin L, Kehu Y, Bin M, Quanlin G, Wang D, Yang L. Iron deficiency anemia in helicobacter pylori infection: meta-analysis of randomized controlled trials. Scand J Gastroenterol. 2010;45(6):12.

Ready to submit your research? Choose BMC and benefit from

- fast, convenient online submission

- thorough peer review by experienced researchers in your field

- rapid publication on acceptance

- support for research data, including large and complex data types

- gold Open Access which fosters wider collaboration and increased citations

- maximum visibility for your research: over $100 \mathrm{M}$ website views per year

At $\mathrm{BMC}$, research is always in progress.

Learn more biomedcentral.com/submissions 